\title{
Sharon Anne Cook \\ Sex, Lies, and Cigarettes: Canadian Women, Smoking, and Visual Culture, 1880-2000
}

Montreal and Kingston: McGill-Queen's University Press, 2012. xvii, 418 pp.

\section{Lara Campbell}

Simon Fraser University

In this richly researched and beautifully illustrated book on smoking culture and anti-smoking activism in Canada over the last century, Sharon Cook argues that to understand the role of smoking in women's lives, historians must look to its attractions and pleasures, its relationship to modernism, and its long visual history. Her work is rooted deeply in the methods and analysis of women's history, drawing on a huge range of archival sources and historical images. But it is also deeply invested with current issues surrounding women's health, both in Canada and internationally, particularly as young women continue to smoke at higher rates than boys. Cook ends with a list of ten recommendations for an honest, historically grounded, and genderspecific anti-smoking curriculum.

The thematic structure of Sex, Lies, and Cigarettes allows Cook to trace long-term changes in visual representations of, and attitudes toward, smoking. This structure is somewhat unique for historical monographs, and it shifts the framework away from periodization to an in-depth exploration of themes such as eroticism, thinness, status, sophistication, education, and feminism. The importance of periodization is not lost, however; in rearticulating the chronological overview for each chapter, it soon becomes clear that shifts in smoking culture can be closely tied to the impact of the First and Second World Wars and the growth of consumer culture in the interwar era. Thus, the growth of smoking in general, and women's smoking in particular, is located firmly in the modernity of the interwar years. Cook also adds flavour by including short, mini-biographies in each chapter, including such luminaries as k.d. lang and Joni Mitchell. Her analysis of Young Woman's Christian Temperance Union (YWCTU) leader and anti-smoking activist Bertha Wright is an exceptional example of young women's moral and political leadership in the late nineteenth century, all the 
more important because their work is so often overshadowed by that of their older, married counterparts in the WCTU. But elites, activists, or celebrities are not the only women profiled; Cook's attentiveness to the material of women's history, such as scrapbooks, yearbooks, photographs, diaries, and letters allows her to bring everyday Canadian women into the larger story. She is particularly attentive to the ways in which gender intersects with categories of racialization, class, and marginalization, showing that the representation of women in cigarette advertising was racialized and sexualized, that increasing rates of smoking were tied to women's public visibility and status in the workforce, and that socially and economically marginalized women have long used smoking to meet specific needs.

Cook carefully incorporates the theoretical literature on visual culture, drawing on the insights of Foucault (particularly his 'technologies of the self') and Butler (especially her discussion of gender performativity) to argue for placing visual images at the centre of her analysis. We learn to smoke, Cook argues, and learn to understand the meaning of the act of smoking, though repeated exposure to modern visual imagery, especially ads, television, film and billboards. The way in which early female film stars held their cigarettes - the angle of the hand, or the shape of the lips and mouth as it exhales smoke — signalled (and still signals) a complex tapestry of meaning related to sexuality, gender, rebellion, power, and resistance.

From this perspective, then, Cook convincingly argues that historians, educators, government policy makers, and health experts must take a hard look at the deeply felt pleasures of smoking. Emphasizing the ways in which young women feel joy and empowerment through the act of smoking might seem counterintuitive in a time when most medical experts are desperately seeking ways to reduce smoking rates and the associated health care costs of disease and illness. Yet Cook's meticulous research demonstrates that tobacco companies have been quite able to draw on those joys and pleasures, subtly working them into the very anti-smoking youth campaigns mandated by court settlements. Perhaps, as Cook suggests, an open acknowledgement of that pleasure and empowerment - rooted in bodily control and discipline, coping mechanisms for stress, feelings of sexual empowerment and sophistication, and social bonding/cohesion - will allow anti-smoking campaigners to address the material and psychological needs of young women. Smokers, Cook suggests, are not just victims, dupes, addicts, or "stupid," as one recent campaign suggested; they are responding to the real anxieties and pressures of a modern and sexualized consumer society while simultaneously attempting to find pleasure in it. The analysis of smoking's link to discourses of sophistication and feminist liberation helps us understand why, even in the face of medical evidence, the very powerful symbol of the cigarette has appealed (and continues to appeal) to young women.

While the book is focused on women's relationship to smoking, Cook also delves into several important discussions of masculinity. She points out how soldiers' need to cope with the boredom and brutality of war relaxed prohibitions around smoking and increased its respectability; how young working-class boys were the main target of reformers; how male consumers might have interpreted the eroticized images on cigarette posters and cigar tins; how the Salvation Army used the manly discourse of 
heroic warfare in its own anti-smoking rhetoric. There is much new material here to encourage future scholars interested in the intersection of masculinity with religion, bodies, health, and sexuality. Furthermore, the book documents an important and fundamental shift in the gendered leadership of anti-smoking campaigns over time: from the moral reformers and proto-feminists of the WCTU to the non-smokers' rights campaigns of the late twentieth-century. Perhaps this shift was linked to changing ideas about women's moral superiority and responsibility for reform, or perhaps to the increased status of health professionals; either way, this transformation points to the need for further historical work on the formation of grassroots social movements, the gender of their leaders, and their relationship to the state. With its sympathetic attentiveness to both the historical and systemic issues surrounding smoking and the agency of young female smokers, Cook has written a seminal book on the history, and future, of both smoking culture and anti-smoking activism. 